\title{
DEFESA NA ACÇÃO CAMBIAL
}

\section{(PARTE PRÁTICA)}

1) Quando estudei a defesa na aç̧ão cambial (Rev. da Fac. v. 19 pags. 189 a 198), examinei os principios fundamentaes que regem a matéria, e procurei demonstrar que ha grande difficuldade, não só em determinar, com breve fórmula legal, quaes os limites da defesa do R., mas tambem em classificar, de modo feliz, tudo quanto póde, na prática, ser apresentado contra a pretensão do $\mathrm{A}$.

Ao estudar os titulos de favor (Rev. da Fac. v. 19 pags. 211 a 223), mostrei que o guia no exame de tão difficil assumpto é, em última analyse a boa fé, comquanto geralmente se diga que, a par de tal criterio, ha o da autonomia $e$ independencia das obrigaçôes cambiaes. Com effeito, o princípio da autonomia $e$ independencia das obrigações cambiaes, foi creado justamente para proteger a boa fé em que se acham terceiros, que receberam uma letra sem grandes investigações, por ser títuto cambial destinado a circular rapidamente. $\mathrm{Si}$, das pessoas que recebem titulos cambiaes, fosse exigida uma investigação cuidadosa e escrupulosa, e portanto demorada, o resultado sería ter-se tirado á letra a sua importantissima qualidade-ser o instrumento das rapidas transacções mercantis Abranda-se pois aqui a applicação do "dormientibus non succurrit jus».

Vou estudar casuisticamente o que póde allegar o R., applicando a este assumpto os principios que anteriormente estabeleci. 
referindo-se antes ao prejuizo, ao engano, ao passo que dólo tem sentido mais subjectivo, trazendo a idéa de perversidade moral, maldade, cormpçâo. A fraude existe, até como resultado de una violencia. Quanda uma letra é extorquida de uma pessoa pela força, póde ella prejudicar a terceiro. No vulgar e conhecido cáso do negociante embaraçado, que cede á ameaça de um credor para alcançar uma concordata, a letrá é nulla pela violencia em relação ao devedor, e peliı fraude em relação aos seus credores prejudicarlos.

Ahi temos um dos muitos casos complexos: letra nulla para um por violencia, para outro por fraude; matéria para invalidar uma letra de cambio em concurso de preferencia, e que nenhum cabimento teria em acção cambial como fraude, mas como simulaçâo. Com effeito um individuo que acceitasse a um cumplice uma letra, para prejudicar aos credores, porleria, quando accionado pelo seu credor, allegar simulação da dívida. Em concurso de credores, allegariam estes fraude das duas partes culpadas, que confeccionaram o título cambial.

Nestes casos de vício de consentimento, aindả mesmo na singular hypothese que figurei de concurso de credores, ha sempre defesa fundada no direito pessoal do réu contra o autor, ná phrase do art. 51.

Por șer caso de direito pessoal do réu, é que a letra, em taes condições, sendo endossada a terceiro de boa fé, póde por elle ser cobrada, e contra ella nada se poderá allegar, nem mesmo em concurso de preferencia, parece-me.

4) A par dos vicios de consentimento, que constituem para Vivante o $1 .{ }^{\circ}$ capitulo das excepções pessoaes, colloca elle os vicios existentes na causa da obrigação cambial.

Vamos passal-os em revista.

5) Com Vivante, mencionaremos a obrigação de causa illegitima, ou antes condemnada pela lei ou pelos principios moraes. Exemplifica Vivante ésta especie de defesa com a letra nascida de jogo, de premio de um delicto, ou de arranjo matrimonial. Com- 
prehende-se quanto arbitrio tem, por vezes, o juiz para decidir que ha immoralidade na causa da obrigação. Seja dicto incidentemente que nutro muita dúvida sobre ser nulla a obrigação nascida de jogo, mesmo de azar, salvo si houve trapaça ou dólo.

Apresenta em $2 .^{\circ}$ logar a letra nascida de um contracto inexistente, como representando o preço, por exemplo, de uma coisa que não foi devidamente vendida. Assim, sí se vende, sem escriptura pública, um immovel, quando, por exceder o valor do bem a $200 \$$, era o instrumento público da substancia do contracto, nulla é a letra que representa o pręo, mas tal defeito só póde ser allegado pelo reu contra o autor que teve delle conhecimento, nunca contra tercerio de boa fé: é excepção pessoal, das de que se occupa a primeira parte do art. 51: defesa fundada no direito pessoal do reu contra o autor. (1)

Já fiz sentir que nossa lei fala de direito pessoal do reu, ao passo que a italiana fala de direito pessoal do autor (eccezioni personali a colui che la esercita). Ja eu disse e repíto: tracta-se de "um facto que modifica apenas a relação de direito entre reu e autor», um facto que em nada altera as relações com os demais interessados na lei, como sejani os terceiros portadores de boa fé. (Rev. da Fac., v. 19, p. 193).

Menciona Vivante, como terceiro caso, o de não ter havido a prestação que representa a origem da letra, como si, por exemplo, não foram entregues as mercadorias, cujo preço é representado pela letra.

A este proposito convem uma explicação. E' da natureza do título cambial que não se ache nelle a referencia a uma contraprestação (Vivante n. 1014), mas isto não impede que se allegue e prove a falta della, por meio de embargos á acção cambial.

Si a contraprestação fosse mencionada na letra, profundamente seriam alterados os principios de Direito Cambial:-ao autor tocaria provar preliminarmente ter

(1) Neste ponto, afastam.se as regras cambiaes das que, regem as obrigaçōes em geral. O cessionario recebe o contracto com a responsabilidade do cedente. 
cumprido tal obrigação, e o terceiro nunca poderia allegar boa fé, pois da contraprestação teria conhecimento pelo teor do título. São essas duas as consequencias que mais interessam ao assumpto deste estudo.

Quanto acabo de dizer acerca do caso de não ser feita a contraprestação, que é o $3 .^{\circ}$ figurado por Vivante, como de vício de causa da obrigaçẫo cambial, é applicavel á hypothese de depender de uma condição a acção cambial, $4 .^{\circ}$ caso por elle referido.

O $5 .^{\circ}$, que é o de ser o título de favor, exige que eu reproduza o que já anteriormente disse sobre tal matéria, combatendo preconceitos assás vulgarizados. As partes que se combinaram para fazerem um título de favor, pódem transferil-o a um terceiro, e este, embora tenha conhecimento da origem da obrigação cambial, póde exercer a acção, sem que ao reu seja licito repellil-o com excepção de que se trata de título de favor, porque, como ensina o grande mestre Vivante «quem firma por favor quer que sua tirma seja tomada a serio, e facilite o desconto da letra» (n.1372). (2)

Si porém é o proprio individuo em cujo favor foi feita letra, quem, abusando do título, apparece como credor da importancia, e autor na acção cambial, póde a victima defender-se, allegando e provando que o título era de favor. Si eu acceito em favor de um amigo, uma letra, sem que seja eu realmente devedor, si o amigo, em vez de descontar o título, move acção cambial contra mim, ou si a acção é movida pelos herdeiros delle, porque ignoravam a origem da letra, posso me defender, embargando a acção com o fundamento de título de favor. Como este caso, outros pódem-se dar, quando ha titulos de favor. Occupei-me do assumpto, embora summarissimamente, na Rev. da Fac., v. 19, pag. 217 , n. 8 .

Ha pois ainda ahi um caso de defesa fundada no direito pessoal de réu contra o autor, defesa que não se póde oppor erga omnes.

(2) O conhecimento que constitue em má fé o $3 .^{\circ}$, é o de origem illicita ou illegal da letra, como si foi ella dada em pagamento de um acto immoral ou criminoso. 
Passarei ao $66^{\circ}$ caso, que é interessante. Como se sabe, a letra póde ser endossada para cobrança, e é das que os bancos denominam letra em commissão. Ha ahi um mandato. Póde porém succeder que, èm vez de se usar no endosso da fórmula-valor em conta -, ou de outra equipollente, seja feito o endosso em branco, como aliás infelizmente sempre exigem os bancos. Nos cásos de má fé, morte ou fallencia do mandatario, embaraçosa é a situação do mandante ou endossante, por constar do título a transferencia da propriedade, e portanto ficar sujeito o endossante á acção cambial.

Póde-se defender contra o mandatario ou seus herdeiros, mas não contra os endossatarios, allegando e provando o que não será facil (3) que o endosso foi feito a título de mandato (4).

Como se:vê, é uma hypothese bem caracteristica da defesa fundadı no direito pessoal do réu contra $o$ autor.

O mesmo se póde dizer, quanto ao $7 .^{\circ}$ e último caso figurado por Vivante, que é o da assignatura em branco.

6) Como muito bem diz Lacerda, ésta enumeração é incompleta. Muitas outras defesas, neste genero, podem apparecer (A Cambial, n." 431). Basta, mencionar os casos por elle lembrados de pasamento, novação, compensiçâao, substituiçâa, confusão, remissão, dilação, e concordata, para prova de quão verdadeira é a sua these.

Já que empirica e casuisticamente tracto da matéria, direi duas palavras sobre taes defesas, valendome das observações do distincto collega.

7) O pagamento merece particular attenção, já para que eu premuna os incautos contra o risco de ter elle de ser feito duas vezes, já para patentear quão difficil é a classificação das defesas, como affirmei nas pags. 193 e segs., v. 19. da Rev. da Fac.

(3) Infelizmente, a!ém de exigirem os bancos o endosso em branco. recusam dar qualquer documento comprobatorio da verdadeira natureza da transacção.

(4) Contra os que, ao receberem o título, tinham notícia do vício, e não são pois portadores de boa fé, ha a excepção de dólo. 
Póde succeder que o pagamento tenha sido feito de accordo com todas as cautelas do Direito Cambial, e, neste caso, póde elle ser allegado erga omnes. Mas, em muitos casos, póde ter havido descuido da parte de quem o realizar, como, por exemplo, si pagou uma parte, e não exigiu que fosse a quantia paga notada no título, ou si foi tal nota lançada numa folha de alongamento, supprimida depois dolosamente pelo credor, ou numa duplicata, ou si fez o devedor pagamento integral, e não pediu restituição do título etc. Os casos mais perigosos para quem paga são o de haver muitas vias, e o de pagamento parcial, pois neste último caso não fica quem paga em posse dos titulos representantes de sua obrigação (Vidari, La Cambiale n. ${ }^{\circ} 257$ ), e no $1 .^{\circ}$ póde esquecer alguma via (D. n. ${ }^{\circ} 2.044$ arts. $16 \mathrm{e}$ $22 \S 2)$.

Ao pagar deve-se exigir além do recibo ou quitação, a entrega de todas as vias e cópias em que haja firmas originaes (tutti i duplicati e le copie contenenti firme originali), e, quem faz pagamento parcial, obterá que conste elle das duplicatas ou cópias, não se esquecendo da possibilidade de serem destacadas as folhas de alongamento (Calamandrei, La Cambiale, n. ${ }^{\circ}$ 124, D. n. ${ }^{\circ} 2.044$ arts. 16 e $22 \S 2$ ).

Darei um exemplo: o último endossatario recebe do sacador parte da quantia devida, segundo o título, e dá-lhe recibo avulso, recebe de qualquer endossante toda a quantia, e entrega-lhe a letra. Este póde cobrar do sacador toda a quantia, e contra elle, salvo o caso de má fé (5), não tem o saccador excepção de pagamento. Tracta-se pois aqui de defesa fundada no direito pessoal do reu contra o autor (art. 51).

Si porem houve todas as cautelas. e foram guardadas, no pagamento, as regras relativas á quitaçẫo em matéria cambial, o pagamento póde ser allegado erga omnes (Lacerda n. 438). Não é facil que occorra tal hypothese, de allegação de pagamento, porque, como uma das cautelas quando se paga, é o recebimento do título, dahi resulta a impossibilidade da propositura da acção cambial, e consequentemente não se dará a op-

(5) Excepção de dólo. 
portunidade de ser apresentada a clefesa (Vidari, La Cambial n. 257). Temos entretanto os casos de tolerar o juiz a propositura da acção sem título, de furto de letra já paga e de depósito da importancia devida (art. 26). Nestas circumstancias, a excepcão de pagamento refere-se verdadeiramente a requisito necessario aa exercicio da acçâo.

Destas últimas observações, conclúo que é defeituosa a classificação do art. 51, pois um mesmo membro póde entrar ora numa classe, ora noutra (Rev. da Fac. v. 19, pags. 193 e segs):

Si houve lançamento de quitação parcial na letra, si tal quitação foi supprimida por meios chimicos, ou pela separação da folha de alongamento, é a defesa fundada em pagamento, dolo ou falsidade? E' erga omnes? Parece caso de cumular a falsidade ao pagamento. Incontestavelmente é erga omnes.

Si o réu depositou certa quantia que o autor julgou insufficiente (R. 737 art. 397 § 3), cono no caso do art. 25 do D. 2.044, póde c autor accionar cambialmente por toda a quantia? Não: só pela restante, em vista dos arts. 394 a 400 do R. 737, devendo o credor, ou levantar, com protesto, a quantia depositada, por ser obrigado a receber pagamento parcial (D. n. 2.044 art. $22 \S 1$ ), ou discutir o depósito (art. 397), o que me parece menos vantajoso, porque a sentença se limita a julgar «não ieito o pagamento" (art. 399), só restando então ao credor o direito de exercer a acção cambial pela totalidade.

Dos casos de novação, compensaçâo, substituiçâa, confissão, remissẫo, dilação e concordata, modos de extincção de quaesquer obrigações, nada de particular ha a dizer, salvo que a substituição exige o mesmo cuidadlo que o pagamento, afim de evitar que tenha o devedor de solver duas vezes o mesmo débito.

8) Vivante considera excepções pessoaes não relativâs á origem da obrigaçấo cambial, mas provenientes de factos posteriores ao nascimento do crédito cambial: a dilaçâo, a remissão, o pagamento, a novaçâo, a compensação, a entrada em conta corrente. (sem a cláusula "salvo embolso") e o dólo. Dessas, a de. dólo é a mais importante, porque é com ella que se con- 
testa que esteja o autor em boa fé. Com frequencia, são as letras maliciosamente passadas, por endosso simulado, a terceiros, contra os quaes não possa o réu allegar defesa fundada no seu direito pessoal contra o transmittente. Cohibe-se ésta fraude com a excepção de dólo: ninguem póde receber título cambial com o intuito de embaraçar a defesa do réu. Diz Vivante: "L'eccezione di dolo si può opporre a chiunque acquista la cambiale, e per togliere al debitore le eccezioni che avrebbe potuto opporre al possessore precedente» (n. 1373).

9) Ha ainda um caso interessante, ideado por Obarrio, e que já se deu neste Estado (V. 2, n. 225).

O caso aqui occorrido é o seguinte: dada uma letra em caução, por meio de endosso que transferia a propriedade, e não com a salutar fórmula "vialor em garantia" (Vivante n. 1136), o credor pignoraticio descontou a letra e falliu. Embora seja responsavel por estellionato (6) o credor pignoraticio endossante (Obarrio n. 225), terá o devedor pignoraticio de pagar ao endossatario todo o valor do título cambial, ainda que nada houvesse recebido do credor pignoraticio, ou que houvesse recebido sómente parte do valor do título. Outra sería a solução, si o endosso fôra por "valor em garantia» (7).

Mais uma vez repito, muitas são as defesas pessoaes além destas: acceitaveis são todas as que extinguem ou paralysam a obrigação, ou impedem seu nascimento, segundo as regras de direito commum (Lacerda n. 430).

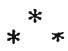

10) Temos, como segunda categoria legal, o defeito de fórma do título (art. 51).

(6) No caso de perda, ou tirada do título contra a vontade do dono, nulla é a transferencia. E' a solução que me parece compativel com o art. 36 do D. n. 2044. Nenhuma incoherencia para a construcção juridica em tal diversidade de soluçōes (Planiol v. 1 ns. 2472,2475 e 2482 . Cogliolo Fil. p. $182 \S 20$ ).

(7) Ahi tambem se accentua a differença entre as regras que dominam as obrigaçōes cambiaes, e as que se referem ás demais obrigações civis e commerciaes. 
Esta locução póde ser tomada num sentido mais restricto, significando sómente a fórma extrinseca (Vivante n. 1370), ou tambem comprehendendo a fórma intrinseca (Lacerda ns. 449 e segs.), ou falsidade, homonymia, defeito ou falta de mandato e incapacidade (Lacerda n. 449, Vivante n. 1370).

Já expliquei que ésta última categoria diz respeito á substancia da obrigação cambial, segundo Vidari, pertence ao direito commum, segundo Vivante, e está na 3. ${ }^{a}$ categoria das enumeradas no art. 51, segundo Saraiva.

Essas excepções são absolutas, erga omnes; mas convém tomar ésta these em termos. Só pódem ellas ser oppostas contra as partes a quem dizem respeito. Assim, si houve um endosso falso, dado por illegitimo procurador, ou por um incapaz, o vício só attinge os endossos posteriores, a letra é plenamente válida «rimpetto ai sottoscrittori posteriori, ma non già verso $i$ precedenti, $i$ quali si potrebbero prevaler di quella eccezione» (Vidari n. 398) (8).

Os defeitos de fórma extrinseca são resultantes da violação da lei cambial, ou mesmo dos principios do Direito Cambial, ou dos preceitos que regem as obrigações em geral (9). São, está claro, visiveis pelo simples exame do título.

Sobre o pouco valor dos instrumento6, em logar substancial, roidos pelos ratos ou traças, apagados pela chuva, escriptos em cifras ou abreviaturas, contendo palavras obscuras ou inintelligiveis, e sobre sua insufficiencia para uma acção violenta, como é a executiva, veja-se Moraes, De Ex. L. 4 c. 2.

Sahiria eu do quadro que me tracei, ao planear este artigo, si descesse a taes minucias.

(8) Com razão pois diz Vidari, quando tracta de excepcōes nascidas de direito pessoal (n. 401) que de algumas dellas já se occupou quando tractou das relativas á substancia da obrigação (ns. 399 e 401).

(9) Ninguem poderá contestar que. na intelligencia do art. 1 do D. n. 2044, muito valem os principios geraes do Direito Commercial e do Direito Civil. O que diz Vivante (n. 1370) de terem os requisitos internos seu fundamento no direito commum, como acima referi, não exclue ésta these. 
11) Os defeitos de fórma intrinseca, como diz, Lacerda (n. 449) ou falta de requisito interno, como diz Saraiva ( $\$ 272)$, ou fórma interna, como diz Supino (Dir. Commerciale n. 343), merecem particular attenção.

Aponta Lacerda, como primeiro, a incapacidade.

Sobre a incapacidade, ha duas observações a fazer.

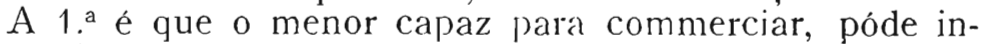
tervir numa letra relativa ao seu commercio por ser emancipado para actos de seu commercio, mas é incapaz para actos da vida civil, e portanto para acceitar letra para negócios extranhos ao commercio para o qual foi autorizado (Vivante v. 1, n. 135).

Como goza do beneficio velleiano a mulher no Brazil, é de concluir que não póde ella ser avalista, pois o aval é méra frança, mas póde ser endossante, pois o endosso não é propriamente fiança, e póde ser dado em proveito do mesmo endossante, e quasi sempre o é.

A 2. ${ }^{a}$ observação é que muito cuidado ha no $\mathrm{Di}^{-}$ reito Civil em determinar quando a incapacidade deve ser conhecida das pessoas que contractam com os incapazes. E' ponto muito melindroso, não obśtante a regra de que cada um deve se informar da capacidade da pessoa com quem contracta. Mais cautela e prudencia deve haver ainda, na applicação deste princípio ás relações mercantis, por serem mais rapidas que as civis.

Quanto á falsidade, é bom ter presente que Vivante a qualifica matéria intrincada (n. 1103). Com effeito, ahi tudo é difficil, até a prova.

O que ha de mais interessante na prática é que a falsidade póde recahir em ponto essencial ou não, e que póde se dar ao tempo da emissão da letra, ou durante sua circulação.

Si a falsidade diz respeito a um ponto accidental, a letra é válida, diz Vivante, mas cada parte: responde nos limites da obrigação que tinha ao tempo em que lancou a firma, porque a falsidade não deve aproveitar nem damnificar a ninguem (n. 1105).

Ainda quando haja falsificação em ponto essencial, nem por isto deixa a letra de ter algum valor. Vivante 
diz que perde a força cambial para as partes que puzeram nella a firma antes da falsificação. Dá como exemplos os casos da alteração da somma a pagar-se, e. da modificação dá epoca do vencimento (Saraiva, A Cambial, \$227).

Está claro, parece, que elle se refere á perda da força de título quanto a produzir acção executiva: o papel será sempre uma prova, embora precaria, do débito, da obrigração das partes cujos nomes nelle se. acham.

Os que lançaram a assignatura, após a falsificação, ficam cambialmente obrigados, em razão do princípio da autonomia das obrigações cambiaes (D. n. 2044, art. 43, Vivante, n. 1104). Observa Vivante, e é bom ter isto sempre presente, que quem adquire uma letra sabendo da sua fálsificação, nershum direito adquire, porque "para quem a conhece, a falsificação torna inexistente a letra». Não dá exemplo, mas eu apresentarei um. A. falsifica, em saque, a lirma de B, ou. modifica a quantia a pagar em letra sacada por B. e de que A. é o portador, ou altera a data do vencimento. no mesmo título. Si consegue passar por endosso a letra, a serie de endossadores e endossatarios vae ficando cambialmente ligada, emquanto as partes ignorarem a falsificação. Aquelle dos endossatarios que souber da falsificação. terá entre as mãos um papel, sem força de letra de cambio (Saraiva, A Cambial, $\S 227)$.

Deixarei ésta especie de defesa, já assás estudada, pois meu intento era lar de cada uma dás excepções. una ligeira notícia, uma vaga idéa.

Não posso porém deixar de aproveitar a opportunidade para, destas considerações sobre a falsidáde, tirar mais uma prova de quão difficil é a classificação das matérias de delesa na acção cambial (Rev da Fac., v. 19, pag 193, n. 6). A falsidade, que é defesa fundada em defeito de fórma do título, toma o aspecto. de defesa fiındada no direito pessoal do autor, pela influencia (lo conhecimento della, por alguma das partes, e pela circumstancia de ser anterior ou posterior á interven rão de algum clos litigantes (autor ou réu na. acção cambial), como parte na letra. 
Não é sempre defesa que se opponha erga omnes.

Como última defesa fundada em defeito de tórma, citam Lacerda (n. 454) e Vivante (n. 1370) a talta de mandato. Vivante occupa-se tambem com a homonymia.

Muito differe o mandato mercantil do civil.

Faz Vivante sentir que quem adquire uma letra de um representante, tem direito de pedir que este exhiba o instrumento de procuração, mas que o instrumento está longe de ser um accessorio indivisivel da letra. O mandato, continúa elle, póde ser verbal ou mesmo tacito (n. 1038).

Refere-se a lei a mandato especial (D. n. 2044, arts. $1, \S 5,8,11$ e 14), mas este mesmo póde ser verbal ou tacito (Vivante n. 1041). Sobre quanto ha de difficil relativamente ao sentido das expressões mandato geral e especial, extende-se Troplong nos n. 273 e segs. da obra «Du Mandat». Não cabem porém taes investigações nos limites deste estudo, destinado unicamente a dar um escorço das várias sortes de defesa na acção cambial. Por este motivo, deixarei tambem de me occupar com saber si ha, ou não mandato tacito (Bento Faria, n. 150 ao art. 141 do Cod. Commercial).

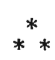

12) Para terminar o exame das excepções a oppor na acção cambial, farei breve referencia ás que assentam na falta de requisito necessario ao exercicio da acção cambial, guardando assim a expressão, a fórmula do art. 51 do D. n. 2044, e sua ordem.

Utilissimo é ter presente que, dessas, algumas tem caracter absoluto, como sejam o pagamento regularmente feito, (Vivante n. 1370), de que acima me occupei, quando me referi a excepções pessoaes, o depósito, a prescripção; e outras têm o caracter de pessoaes, como as de pagamento sem as precisas cautelas, e a de dolo, que já chamaram minha attenção entre as fundadas em direito pessoal do reu contra $o$ autor. Não me deterei em tal exame theorico, porque quero dar a este artigo caracter, quanto possivel, prático, casuistico, empirico. 
As que melhor entram na última categoria do art. 51 são as mencionadas por Lacerda (n. 455), e de que passo a occupar-me.

13) Antes porém terei de determinar a classificação dessas especies de defesa, assumpto com que não me occupei na $1 .^{\mathrm{a}}$ parte deste estudo (Rev. da Fac., v. 19, pags. 193 e segs.).

Eis as classes :

1 Matéria de processo geral.

2 Matéria de Direito Cambial.

A $1 .^{a}$ classe subdivide-se em:

1 Excepcões no sentido restricto, materia prejudicial pela lei (R. 737 art. 74).

2 Embargos quanto ao fundo do pleito, ou matéria que a lei nâo julga prejudicial.

Isto posto, ha, antes de tudo, a consignar que, no processo executivo, é licito offerecer excepçoes durante o prazo assignado para embargos (Lobão. Pr. Ex. § 193, Ram., Pract. P, 4 T $1 \S \S 2$ e 4, Sylva L. 3 T 88 pr. n. 9), tomando o vocabulo excepção no sentido de matéria considerada pela lei como prejudicial. (10)

As unicas allegações deste genero são hoje: 1 incompetencia e suspeiçâa, 2 illegitimidade das par tes, 3 litispendencia e 4 coisa julgada (R. 737 arts. 74 e 75). Rejeitada a excepção, será assignado novo termo ao réu (R. 737 art. 80).

14) Passando das excepções, matéria prejudicial por lei, á defesa offerecida em embargos, encontra-se um ponto muito pouco claro no nosso Direito Processual, qual o relativo a embargos suspensivos ou não, recebidos nos mesmos autos, ou em apartado. $\mathrm{O} R$. 747, nos arts. 577, 578 e 582, é expresso, admittindo embargos em apartado nas execuções.

Quanto ás acções executivas, a regra é que sejam os embargos recebidos nos proprios autos, com sus-

(10) O rocabulo significa, no sentido geral, qualquer defesa 
pensão do processo, como mostra o grande Lobão, (Pr. Ex. $\S \S 186$ e segs). Creio entretanto que ha dois casos em que pódem os embargos ser recebidos em auto apartado nas acçõès executivas.

O $1 .^{\circ}$ é o de serem frivolos, calumniosos e inconcludentes, (Lobão, Pr. Ex. § 189), ao que eu accrescentarei o de não estarem comprehendidos na fórmula, alias ampla, do art. 51 do D. n. 2044. O 2. ${ }^{\circ}$ caso é o de não ter o réu provado, já não digo cumpridamente (R. 737 art. 258), mas de modo a evitar a supposição de intuito protelatorio, os seus embargos (R. 737 arts. 313 e 314). Não posso dar outra intelligencia ao art. 313, não obstante o seu apparente caracter facultativo. Não me consta que se tenha dado, no nosso fôro, caso de recebimento de embargos em apartado, nem em acçâo executiva, nem en execução.

15) Ha ainরla, como digna de attenção, uma difficuldade que tem surgido nas acções executivas hypothecárias: pódem ser apresentados, na $2 .^{2}$ phase do processo executivo (que é a posterior ao julgamento da penhora), embargos referentes á 1. ${ }^{a}$ phase ? Não, decidiu sempre o Tribunal de S. Paulo. Afasto-me deste modo de entender o art. 578 de R. 737, e algures produzi os seguintes argumentos:

«I Nada mais fez o reg. n. 737 do que autorizar, e regular a opposição de embargos após o julgamento da penhora, direito que muitos jurisconsultos contestavam ao executado. (Lobão, Ex. $\S \S 405$ e segs., L. Velho art. 341.

O intuito do nosso legislador era pois ampliar, e não restringir a defesa.

II O processo é indivisivel, e de tal ordem é ésta indivisibilidade que, ainda na execução, se conhece de matéria referente á acção principal (Reg. n. 737 arts. 581 e 583): como pois separar mais accentuadamente a execução em duas partes, do que a lei separa a execução da acção principal?

III Bem póde succeder que, na primeira phase, tenha tido o executado justo impedimento. (Moraes, Ex., L. 6 C 9 n. 11). 
IV A's vezes, a nullidade da primeira phase affecta a segunda: como sustentar, em tal caso, a doutrina contrária, em face do art. 674 do reg. n. 737, vers. em qualquer tempo?

Quanto á acção executiva, ha ainda mais estes argumentos.

I Não teve ainda o R. o prazo para a defesa, que, na acção, teve o executado: posição a do R., em acção executiva, deve pois ser ainda melhor que a do executado.

II Pela doutrina dos nossos adversarios, nunca poderá o R., em acção executiva, usar de embargos á sentença, sendo para elle letra morta o art. 577 \$ 8 clo reg. n. 737, de que só poderá se valer o executado. Inutil encarecer o que ha nisto de injusto".

16) Desbravado o caminho, passarei a occupar-me dos varios modos de atacar a acção.

A matéria de Processo Geral, quanto ao fundo do pleito, está determinada nos arts. 577 e segs. do R. 737 salvo o que de inapplicavel tem á acção de que nasceu a execução, (art. $577 \$ 8$ ), ou o que entra noutra classe de defesa, como, por exemplo, a matéria do art. $577 \S 5$.

17) Quanto á falta de requisito para o exercicio da aç̧ão em referencia particularmente ao disposto no Direito Cambial, é feliz, parece-me, a enumeração de Lacerda (n. 455).

A $1 .{ }^{\text {a }}$ defesa por elle apresentada é de não exhibição da letra com os requisitos essenciaes.

Está claro que o título restaurado suppre o original extraviado ou destruido, em vista do art. 36 \& 4 do D. n. 2044, que dá ao proprietario habilitado a faculdade de mover acção executiva pela sentença que declara annullado o título primitivo.

Esta fórma de defesa tem o seu assento nos arts. 69, 309 e 720 do R. 737.

A 2. ${ }^{\text {a }}$ defesa apontada por Lacerda é a da illeg $i$ timidade da parte. Occorre no caso de não ter o autor direito a receber o pagamento, e funda-se nos arts. 23, 39, 40 e $\div 1$ do D. n. 2044. 
Como é bem de ver, póde-se allegar tal defesa como preliminar ou prejudicial, ou como excepcão no sentido restricto (R. 737 art. $7+\S 2$ ). Esta defesa acode a muitas necessidades dá prática, podendo dar resultado até sobre a identidade das pessoas mencionadas no instrumento "an sint eœedem de quibus instrumentum loquitur» (Moraes, De Ex., L 3 c 2 n. 1).

A $3 .^{a}$ defesa é a de extinç̧ão da cambial por pagamento ou termo extinctivo.

Quanto ao pagamento, já fiz ver quanto é difficil determinar a que classe de defesas pertence elle.

Do termo extinctivo direi sómente que occorre, quando houve de parte de algum interessado na letra, falta de cumprimento a tempo de certas formalidades legaes, como a apresentação (art. 9).

A fórmula adoptada por Lacerda não abrange o caso de ser proposta acção executiva por endosso posterior ao vencimento (D. n. ${ }^{\circ} 2044$ art. $8 \$ 2$ ). $E^{\circ}$ entretanto um caso em que póde o réu excluir a acção cambial, exigindo que o autor use da ordinaria. Em tal hypothese, não ha propriamente extincção da letra, que apenas perde parte de sua força como instrumento probatorio de débito. Ha porém, é certo, extincção da acção cambial.

Poderia, parece-me, reunir Lacerda, ésta $3 .^{\text {a }}$ defesa á immediata de que vou me occupar, dizendo sómente letra prejudicada, dando á expressão o sentido que lhe dá T. de Freitas, letra que não faz as vezes de dinheiro, por outra, que não póde ser endossada com incremento de garantia» (Add. p. 732), ou dizendo letra prejudicada ou endossada após o vencimento, dando á expressão prejudicada o sentido que lhe dá Orlando «letra em que o dono ou portador deixou de praticar alguma formalidade legal» (Orlando, n. ${ }^{\mathrm{a}} 523$ ao art 364, Cod. Commercial).

(1) No rigor de Direito, parte illegitima é a que não póde sigurar em juizo por si mesma. ou por si só, ou sem que precedão certas condições lenaes (P. Bueno, Apont., n. 48, Pereira e Souza, Primeiras Linhas $\$ \$ 12 \equiv$ e 126). Hoje entendemos por parte illegitima a que não póde se considerar titular do direito reclamado pela acção, ou noutros termos, a parte incompetente para propor a acção. 
Deixando porém quaesquer investigações de caracter theorico, (12) o que é certo é que o réu póde allegar falta de qualquer formalidade legal que tenha como consequencia perder o portador da acção cambial contra algum, ou contra todos os obrigados na letra, como quando não houve apresentação a tempo (art. 9), ou não se fez protesto em fórma legal (art 32), ou endossou-se a letra já vencida (art. $8 \$ 2$ ).

A $4 .^{a}$ defesa apresentada por Lacerda é a de falta ou nullidade do protesto.

E' a que poderia se reunir como acabo de dizer, creio, com a anterior, formando ambas uma só classe.

Pela falta de protesto fica o portador privado do direito de acção cambial por via de regresso contra o sacador, endossador e avalistas (art. 32). Só the resta acção cambial directa contra o acceitante, ou seu avalista, e isto mesmo só pelo principal. Não tem direito a juros sinão a contar da data em que judicialmente exigir o cumprimento da obrigação cambial (Cod. Commercial, art. 138).

A $5 .^{a}$ defesa, que é a de prescripção, nenhuma particularidade processual offerece na acção cambial. Ha ainda uma questão de interesse prático: póde o juiz supprir, na acção cambial, a defesa que o réu omittiu ? Não, em vista do art. 312 do R. 737.

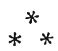

18) No estudo que, do ponto de vista concreto, casuistico, empirico, processual, prático, acabo de fazer das matérias que pódem constituir a defesa na acção cambial, nada mais ha do que o desenvolvimento, a applicação dos principios que apresentei no estudo abstracto, formal, theorico. doutrinal que se vê na Rev. da Fac., v. 19, pags. 189 a 198.

Si, dos principios, passei á applicação, poderei agora, do exame analytico remontar aos principios. Ha nisto vantagem, porque, como diz Cogliolo, na analyse sempre se perde alguma coisa, que é a synthese.

(12) E' conhecida a disputa entre T. de Freitas e Orlando sobre o sentido da expressão letra prejudicada. 
Recapitulando pois, direi, que, pelo exame dos casos occurrentes na defesa em acção cambial, fica provado que alguns, como o pagamento, a incapacidade das partes, o vício de origem, ora dizem respeito a umas partes, ora a todas, e que portanto a classificação das defesas feita por Vivante é defeituosa, embora seja a melhor. Tambem tornou-se incontestavel que defeitos de fórma intrinseca, ou de substancia, ou de fórma interna, como a incapacidade e a falsidade formal, do mesmo modo que os de fórma extrinseca, como a falsidade material, pódem constituir direito pessoal do réu para com o autor, e portanto é defeituosa a classificação da lei (art. 51).

Bem apurado, as defesas fundadas em direito pessoal do réu de que fala a lei (art. 51) são as mesmas in personam de que fala Vivante, mas, na classificação,olhou o legislador mais á origem, e Vivante mais aos effeitos. Restam as demais que Vivante considera erga omnes, e que a lei reparte em nascidas de vício de fórma, ou de falta de requisito para o exercicio da acção, subdivisão que se póde evitar.

Com que fórmula enfeixar as últimas?

Propõe Vivante ésta: "opponibili a qualsiasi possessore».

.Para as outras propõe estoutra: "personali a chi esercita il credito». E' o que se póde fazer de mais. perfeito na difficil matéria, ou de menos imperfeito.

Ainda ha uma conclusão a tirar deste meu trabalho analytico.

Todos os que conhecem a evolução por que tem passado a defesa na acção cambial, devem ter notado que é ella hoje muito mais ampla do que no regimen do R. 737, e que era ainda mais restricta antes de 1850.

Seguro o juizo, entendeu-se dar grande amplitude á defesa. Seus limites são o princípio da autonomia e independencia das obrigações cambiaes (art. 43) e o da boa fé; mas, em última analyse, é a boa fé que tudo domina. Combinando-se a boa fé com a celeridade mercantil, attendendo-se á necessidade da rapidez das transacções mercantis, creou-se o principio da autonomia e independencia das obrigações cambiaes (art. 43) 
e attribuiu-se ás obrigações cambiaes o caracter de $a b s$ tractas, dando brilho, vigor e nova vida á obrigação que, em Roma, nascia da stipulatio (Dernburgo, Obr. $\$ 22$ ). Reconheceu-se que a letra de cambio sería insufficiente para as necessidades do commercio, si os terceiros tivessem de investigar cuidadosamente qual a origem da obrigação, e dahi o favor aos terceiros de boa fé no Direito Cambial, favor que só cessa quando, pela excepção de dólo, se mostra que o terceiro realmente conhecia o vício original da transacçāo.

Diversamente se passam as coisas nas de mais obrigações civis e commerciaes. Cada cessionario deve investigar o que ha em relação á dívida originária. Com o recurso dos registos estabelecidos pelo direito hodierno, mais severa se tem tornada a lei em relação ás pessoas que adquirem bens corporeos e direitos, sem o devido exame dos titulos originaes.

Ha uma antithese emfim a pôr em evidencia. Comparando a defesa na acção cambial com a tolerada nas acções ordinarias, vemos que é muito menos ampla, não obstante o desenvolvimento que teve em 1850 (R. 737) e em 1908 (D. n. 2044).

Ao interpretar o D. n. 2044, cumpre ter presente que elle reformou, por completo, a antiga construcção do instituto cambial:

Ultima Cumoi venit jam carminis oetas;

Magnus ab integro soclorum nascitur ordo.

Alguma reluctancia ha de encontrar, na sua applicação, o D. n. 2044, como encontrou o regimen hypothecario de 1864. Mas, si já não tem hoje a nova construcção do instituto hypothecario sinão admiradores e até fanaticos, outro tanto succederá, em futuro muito proximo, com o novo regimen cambial.

Então terei o ineffavel prazer de ter sido dos primeiros a proclamar-lhe a excellencia.

Dr. JoÃo Arruda. 